Brit. J. industr. Med., 1965, 22, 270.

\title{
A CONTINUOUSLY RECORDING ATMOSPHERIC CARBON MONOXIDE MONITORING SYSTEM WITH FULLY AUTOMATIC ALARMS IN A BLAST FURNACE AREA
}

\author{
BY \\ G. M. DAVIES, ${ }^{*}$ J. GRAHAM JONES, and C. G. WARNER* \\ From the Occupational Hygiene Unit, Medical Department, Richard Thomas and Baldwins, Ltd., Ebbw Vale, Mon.
}

(RECEIVED FOR PUBLICATION APRIL 30, 1965)

\begin{abstract}
A continuously recording carbon monoxide monitoring system with fully automatic alarms is described for use in blast furnace areas. The equipment comprised the Mines Safety Appliances Model 200 infra-red analyser, pumping system, recorder, extension meter, and alarm unit.

Use of the apparatus showed that concentrations of carbon monoxide in the blast furnace area studied were mostly in the range of 0 to 49 p.p.m. Readings of 200 p.p.m. and over generally indicated that some abnormal and potentially dangerous incident had occurred. Examples of such incidents are given.

A visual alarm was set at 200 p.p.m., a level at which work could safely continue for a limited period, and an auditory alarm at 500 p.p.m., at which level immediate action was necessary. The theoretical reasons for selecting these levels are discussed, and practical results are quoted to confirm their suitability.
\end{abstract}

The smelting of iron ore in a blast furnace is accompanied by the evolution of about six tons of blast furnace gas for every ton of iron produced (Memorandum on Carbon Monoxide Poisoning, 1951). The gas, which contains about $27 \%$ of carbon monoxide by volume, is used as a fuel to provide heat and power for the blast furnace and subsequent steel-making operations. There is an ever-present risk of carbon monoxide poisoning to those engaged in the blast furnace process and in the handling and disposal of such enormous volumes of gas. Safe working practices and strict supervision on all jobs reduce the risk, but, as is shown in Table 1 , fatal gassing accidents and others sufficiently severe to require reporting to the Factory Department continue to occur. It is difficult to obtain exact information concerning the number of cases which are not reported. However, from practical experience, it appears that for every reported case there are approximately 100 other cases of gassing of varying degrees of severity. It is also known that even under 'normal' working conditions, the carboxyhaemoglobin levels of blast furnace personnel are signifi-

* Present address: Department of Social and Occupational Medicine, Welsh National School of Medicine.
TABLE 1

GASSING ACCIDENTS DUE TO BLAST FURNACE GAS

\begin{tabular}{c|c|c}
\hline Year & Fatal & Total \\
\hline 1945 & 1 & 37 \\
1950 & 15 & 62 \\
1959 & 2 & 13 \\
1960 & 7 & 25 \\
1961 & 4 & 15 \\
1962 & 4 & 18 \\
1963 & 1 & 16 \\
\hline
\end{tabular}

Taken from the Annual Report of H.M. Chief Inspector of Factories on Industrial Health, 1963.

cantly higher than the average levels found in the population as a whole (Farmer and Crittenden, 1929; Jones and Walters, 1962).

Clean blast furnace gas cannot be recognized by smell, and, consequently, the first intimation of the presence of the gas may be symptoms of poisoning, such as headache, nausea, weakness or collapse. In high concentrations the onset of poisoning may be so rapid that the person is unable to move to an uncontaminated area and, if not rescued within a short period, may be fatally affected.

Evaluation and control of the health and safety hazard caused by carbon monoxide depend primarily on detection and quantitative determination of the 270 
gas in the atmosphere. Methods for detecting and estimating carbon monoxide may be chemical, chemico-physical or physical. Beatty (1955) described the various methods available, and since then the development of gas chromatography has provided the only basically new method.

Many of the instruments and procedures use oxidizing reagents to oxidize carbon monoxide, either stoichiometrically or catalytically, with the formation of carbon dioxide, liberated iodine or liberated heat of oxidation which can be measured. Most of the colorimetric methods are based on the reduction of palladium salts to form black metallic palladium or, if ammonium molybdenate is incorporated in the reagent, molybdenum blue. The thermal conductivity method is based on measurements of the change in resistance of a heated wire as the result of heat lost by thermal conductance through the gaseous atmosphere surrounding the wire. Electroconductivity methods involve the combustion of carbon monoxide to carbon dioxide and absorption of the latter into alkaline solutions in which electro-conductrimetric measurements are made before and after the absorption. Infra-red gas analysis and gas chromatography provide other methods.

Some of the methods mentioned are suitable for analysing single samples, whereas others may be adapted to provide continuous sampling. The usefulness of these latter methods depends to a great extent on the speed of analysis and whether they can be made fully automatic or require the attention of a technician.

The methods currently in use around blast furnaces in Great Britain are either spot sampling colorimetric methods or continuous sampling for a limited period, using a portable instrument depending on the hopcalite catalytic method. The lay-out of a blast furnace department is complex, and contamination of the surrounding atmosphere may occur from many different sources, including the furnaces themselves, gas mains, stoves, dust catchers, and cleaning plant. Many of these sources are in the open and climatic conditions influence the movement and dispersal of blast furnace gas in the air. Atmospheric conditions at a given point can vary from minute to minute and, because of this, spot sampling is of very little value as a safety measure. A portable continuous sampling instrument is of use in monitoring a limited area. Both methods have the disadvantage that normally the operator must be with the instrument in the possibly contaminated atmosphere and, although an extension tube may be fitted, this makes the sampling procedure more difficult.

To ensure the safety of blast furnace personnel, the working atmosphere should be monitored con- tinuously for the presence of carbon monoxide, an alarm system provided to warn of dangerous concentrations, and clear instructions given concerning action to be taken on receipt of the alarm. To achieve this end, it is necessary to adopt a method of determining carbon monoxide concentrations in the atmosphere which has the following characteristics:

(a) It should be sufficiently accurate in the range of concentrations from a safe level to that at which immediate withdrawal from the atmosphere is essential.

(b) It should be selective for carbon monoxide in the presence of other airborne blast furnace contaminants.

(c) The time of analysis should be as short as possible.

(d) The time taken for the sample to reach the instrument should be as short as possible.

(e) It should be fully automatic.

$(f)$ It should suit the requirements of multi-point sampling.

(g) The result of the analysis should be immediately available in visual form.

(h) It should be suitable for connexion to an alarm system.

(j) Routine maintenance and calibration time should not be excessive.

The most suitable method to satisfy these requirements was considered to be infra-red gas analysis. This was used in the work to be described which was carried out in a blast furnace department at one of the works of Richard Thomas and Baldwins, Ltd. during 1963.

\section{Monitoring Equipment}

The necessary equipment consisted of an infra-red analyser, pumping system, recorder, extension meter, and alarm unit.

The infra-red analyser chosen was the Mines Safety Appliances Model 200. This was selective for carbon monoxide, had a response which was virtually instantaneous, and over a range of 0 to 1,000 p.p.m. had an accuracy and sensitivity of $1 \%$ of full-scale deflection, i.e., 10 p.p.m. It was mounted on a panel (Fig. 1) located in a building conveniently sited in relation to the area to be monitored.

A pumping circuit fed the atmosphere to be analysed into the sample cell. Six points at distances of up to $300 \mathrm{ft}$. $(91 \mathrm{~m}$.) from the analyser were sampled continuously through $\frac{1}{4}$ in. $(6 \cdot 35 \mathrm{~mm}$.) internal diameter copper tubing by a pump situated at the instrument, the longest line being cleared in approximately one minute. Filters at each end of the lines protected the analyser against the ingress of particulate matter and moisture. Samples from each line were in turn switched, by means of electrically operated valves, into the sample cell of the 


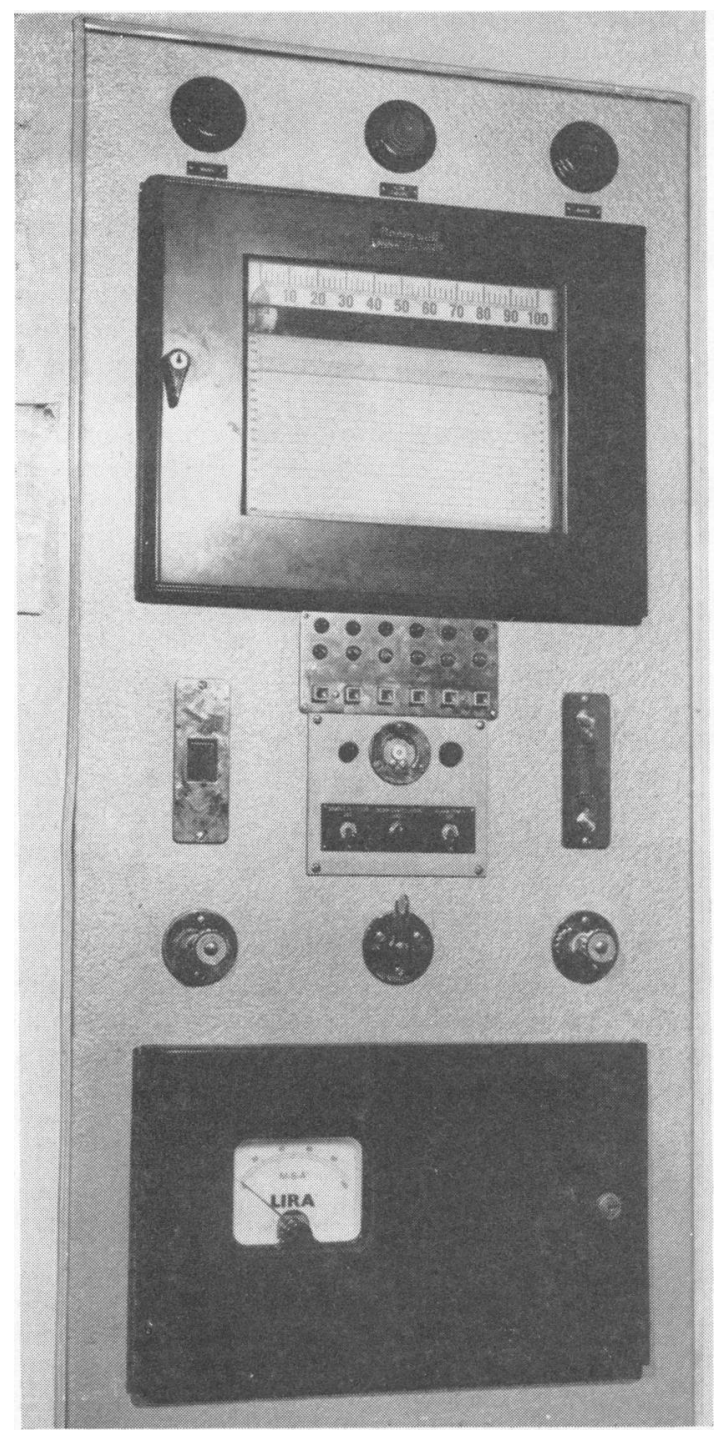

FIG. 1.-Instrument panel.

analyser, each sample being preceded by a purging volume of clean air. The complete cycle for the six lines took two and a half minutes.

The amplified signal from the analyser was fed to a metering circuit and could be presented simultaneously on the panel meter, an extension meter, and a Honeywell recorder, each of which had a range of 0 to 1,000 p.p.m. The recorder had a single movement but could record six points successively, and its controlling circuit was synchronized to the circuit operating the valves in the sampling lines. Thus the chart recording displayed the carbon monoxide concentration of the atmosphere in the line being sampled and indicated from which of six points the sample had been taken.

Visual and auditory alarms were operated by the metering circuit. If the lower alarm level was exceeded, two bulbs lit up, one on the instrument panel and the other at the point being sampled. These stayed on until the sampling cycle reached the position immediately preceding the line concerned, when they were switched off ready to re-register if necessary when the line was sampled again. If the higher level was exceeded, klaxons were energized at the instrument position and in the blast furnace area.

The extension meter could be plugged into one of four sockets conveniently sited in the blast furnace area, placing it in series with the panel meter and the recorder.

The instrument was primarily intended to be used as a continuously recording carbon monoxide monitoring device with fully automatic alarms. As such it would give warning if alarm levels were exceeded at any of the six sampling points. In addition, by intelligent interpretation of the chart, much more information on carbon monoxide levels in the blast furnace area and their association with changing local conditions could be obtained.

By stopping the cycling mechanism at one particular sampling point, it was possible to obtain a continuous reading for that point. Rubber tubing up to $300 \mathrm{ft}$. $(91 \mathrm{~m}$.) in length could be attached to the point, and using the portable extension meter, it was possible to obtain a continuous reading wherever the end of the tubing was placed. The instrument could therefore be used in the routine checking of plant or in specific areas where gas leaks were suspected. Similarly, it could be used as a monitoring device during maintenance work in an area where gas might be expected.

Air samples collected by other means could also be analysed.

During the commissioning of the instrument, certain components proved faulty and had to be replaced. Subsequently, however, when the instrument was established, it required no more maintenance than other steelworks electronic instruments. Checks for accuracy with, first, an atmosphere containing no carbon monoxide and, secondly, a known concentration of carbon monoxide were originally carried out daily, but eventually weekly checks proved satisfactory.

It became apparent that responsibility for supervision of the system lay in three directions. Maintenance and calibration of the instrument should be the responsibility of the works instrument engineer. Action to be taken on receipt of alarms should be the responsibility of blast furnace management. Thirdly, collection and analysis of the running records should be the responsibility of the occupational hygienist, if available, but otherwise a scientific department, such as Operational Research, should accept this responsibility and circulate summarized information to production, engineering, medical, and other interested departments.

\section{Alarm Levels}

At the request of the manufacturers, provisional alarm levels were chosen before installation. Our 


\section{CARBON MONOXIDE MONITORING}

decision was based in the first place on the effects of known concentrations of carbon monoxide on man. Additionally, indirect evidence from the study of carboxyhaemoglobin levels in blast furnace workers gave some help in assessing the atmospheric concentrations of carbon monoxide likely to be encountered. After consideration of the limited data, the levels of 200 p.p.m. for a visual warning and 500 p.p.m. for an auditory warning were accepted for the following reasons.

Purposes of the Alarm System.-The alarm system had two main purposes-to warn blast furnace personnel of dangerous or potentially dangerous concentrations of carbon monoxide, and to alert those responsible for ensuring safe working conditions. It was obvious that an auditory alarm would alert everyone on the plant and a visual alarm would alert those in the vicinity of the sampling point.

Therefore it was decided that the auditory alarm should be set at a level at which immediate action would be necessary, both by those exposed to the carbon monoxide and by those responsible for restoring a safe atmosphere. Those in the area would withdraw or protect themselves with breathing apparatus, and those responsible for safety would take immediate action to control the source of the carbon monoxide.

It was agreed that the visual alarm should be set at a lower level at which work could safely continue for a limited period. Those in the area would be warned that a dangerous concentration might be reached and would also be instructed to inform a responsible person whose duty it would be to investigate.

Effects of Known Concentrations of Carbon Monoxide on Man.- The maximum allowable concentration of carbon monoxide recommended by the American Conference of Governmental Industrial Hygienists (1964) for moderate working over an eight-hour shift is 100 p.p.m. This recommendation has been made and reviewed annually in the light of all available relevant information and we accepted it as the most important factor in our deliberations. Recently, Schulte (1963) speculated on the need for reducing the level as a result of his findings that impairment of psychomotor skills can be detected in subjects exposed to an atmosphere containing 100 p.p.m. of carbon monoxide. However, in the same study he confirmed the findings of many previous workers, that subjective symptoms did not occur, nor were any physiological activities affected at levels of carboxyhaemoglobin below $20 \%$, which was the maximum concentration measured during his tests.
SYSTEM IN A BLAST FURNACE AREA 273

Spencer (1962) published a graph showing the effects on man of concentrations of carbon monoxide ranging from 100 to 2,500 p.p.m., the figures being taken from various authors, although these were not named. This graph shows that concentrations of 100 p.p.m. do not give any symptoms of carbon monoxide poisoning after $2 \mathrm{hr} .30 \mathrm{~min}$. exposure while working. Exposure to 200 p.p.m. while working leads to headache after approximately one hour and there are no further symptoms after $2 \mathrm{hr} .30 \mathrm{~min}$.; 300 p.p.m. causes headache after $30 \mathrm{~min}$., leading to possible dizziness, nausea, weakness, and collapse after one hour. Similar symptoms occur progressively earlier up to 500 p.p.m., above which concentration it is shown that unconsciousness and death may occur after an exposure of one hour. At a concentration of 500 p.p.m. the symptom of headache is produced after approximately 20 minutes.

All this information was applicable to exposure to constant levels of carbon monoxide in the atmosphere breathed. For the purpose of this study it had to be considered in relation to exposure to fluctuating concentrations about which originally we had no exact knowledge. We could find no direct information on the subject and decided to accept indirect evidence available in the few studies of carbon monoxide absorption in blast furnace workers.

Carboxyhaemoglobin Levels in Blast Furnace Workers.-Carboxyhaemoglobin levels from 1.5 to $18.1 \%$ were found by Farmer and Crittenden (1929) in 14 blast furnace workers carrying out normal duties. Jones and Walters (1962) obtained readings ranging from 2.3 to $14.9 \%$ from 57 blast furnace workers. In neither series did any worker complain of symptoms.

Practical experience by one of us in the medical supervision of blast furnace workers over a period of 15 years had shown that in all cases of carbon monoxide poisoning causing symptoms there had been a definite abnormal happening and the source of the gas could be traced. In eight cases of poisoning where accurate carboxyhaemoglobin readings were available, concentrations ranged from 24 to $39 \%$.

From this we deduced that under 'normal' working conditions, although carbon monoxide was absorbed and could be demonstrated in the blood, a level of $20 \%$ carboxyhaemoglobin was not exceeded and symptoms were not produced. Additionally, we considered that this indicated that an eight-hour exposure to fluctuating concentrations of carbon monoxide under 'normal' blast furnace conditions produced carboxyhaemoglobin levels slightly below those produced by an eight-hour exposure to a constant level of the M.A.C. value, 100 p.p.m. 
Chronic Carbon Monoxide Poisoning.-To mention chronic carbon monoxide poisoning is to invite argument. Pfrender (1962) finishes a critical study of the literature on the subject by saying '. . . the existence of chronic carbon monoxide poisoning remains almost a matter of personal opinion'. Included in the criteria laid down by Katz (1958) for considering this diagnosis is the necessity for the blood level of carbon monoxide to be $10 \%$ or more. As has been mentioned above, this level can be exceeded under 'normal' blast furnace working conditions and under experimental conditions by a subject inhaling air containing 100 p.p.m. of carbon monoxide.

It was obvious that, whatever our views on chronic carbon monoxide poisoning, atmospheric conditions capable of producing carboxyhaemoglobin levels of up to $18 \%$ were not wholly acceptable. However, our immediate problem was to establish realistic alarm levels which would help to protect workers from more obvious ill-effects. We therefore decided to ignore chronic poisoning with the proviso that, in the light of information which might be obtained from further study of blast furnace workers, we would be prepared to review our decision.

Lower Alarm Level.-Having agreed to accept a lower alarm level which would protect workmen from obvious symptoms of carbon monoxide poisoning, but which did not preclude the possibility of chronic poisoning or psychomotor impairment, we had to decide on a figure applicable to fluctuating concentrations which would be equivalent to or better than the M.A.C. of 100 p.p.m. for constant levels. A completely logical decision could not be made on the limited information available, and an estimate erring on the side of caution was necessary.

The relevant facts and their implications appeared to be as follows:

(a) Because of fluctuations in concentration, the level would be above 100 p.p.m. The extent to which this concentration could be exceeded depended on two unknown factors, viz., the degree of fluctuation and the total effect of inhalation during an eighthour period of varying concentrations, up to the limit of the chosen level.

(b) The atmosphere would be sampled in one particular area once every two and a half minutes, or 24 times in an hour. The warning level should be kept low enough to take account of the element of chance whereby only a low level in the fluctuations might occur when the area was being sampled.

(c) At a constant level of 200 p.p.m. approximately one hour would elapse before the appearance of the first symptom of poisoning.

(d) A safety margin would be provided by the fact that in the course of their duties men changed locations frequently and spent considerable periods in areas free of gas or where its presence was extremely unlikely.

(e) From the practical point of view, it was important to avoid unnecessary warnings and, consequently, the chosen level should be as high as possible within the safe limits.

The safety advantages provided by fluctuations of concentrations and changes of location of men exposed had to be assessed against the limitation imposed by the sampling frequency of 24 times per hour. In this latter respect, if the concentration was persistently above the warning level, the alarm would be given on each sampling occasion. A problem arose only if concentrations fluctuated around the warning level. This required a decision on the length of time necessary to ensure that the warning level was exceeded on a sampling occasion and during which the atmosphere could be inhaled without producing symptoms. We considered a period of one hour satisfactory in this respect and consequently accepted 200 p.p.m. as the lower warning level.

Upper Alarm Level.-The main point for consideration in establishing the upper alarm level was the speed of contamination of the atmosphere. It was clear that concentrations could build up slowly or quickly, depending on the source, and we decided that a large safety margin was required, i.e., that the level should err on the low side. As previously noted, concentrations of 500 p.p.m. could be inhaled continuously for $20 \mathrm{~min}$. before the symptom of headache was produced, and consequently we decided that a warning at this level would allow time for safe withdrawal to a clear atmosphere.

\section{Field Trials}

Initially, the cycling mechanism was not used and an extension probe of rubber tubing was run out directly from the control panel of the apparatus. Exploratory readings were taken at 14 points (coded G to U, Fig. 2) around the blast furnace area. The results obtained during a total sampling time of 76 hours for all 14 points are shown in Table 2.

In the light of these findings and knowledge of plant lay-out, the provisional siting of the six fixed points was agreed mutually in discussion with production and engineering staff. Sites 1 to 4 were on the $\mathrm{N} / \mathrm{S}$ line along the main walkway through the furnaces and stoves area. Sites 5 and 6 were near the hoist houses of furnaces 3 and 2 respectively. They are shown in Fig. 2 by the numbers in square boxes. The copper tubing lines joining these points to the control panel were then installed. 


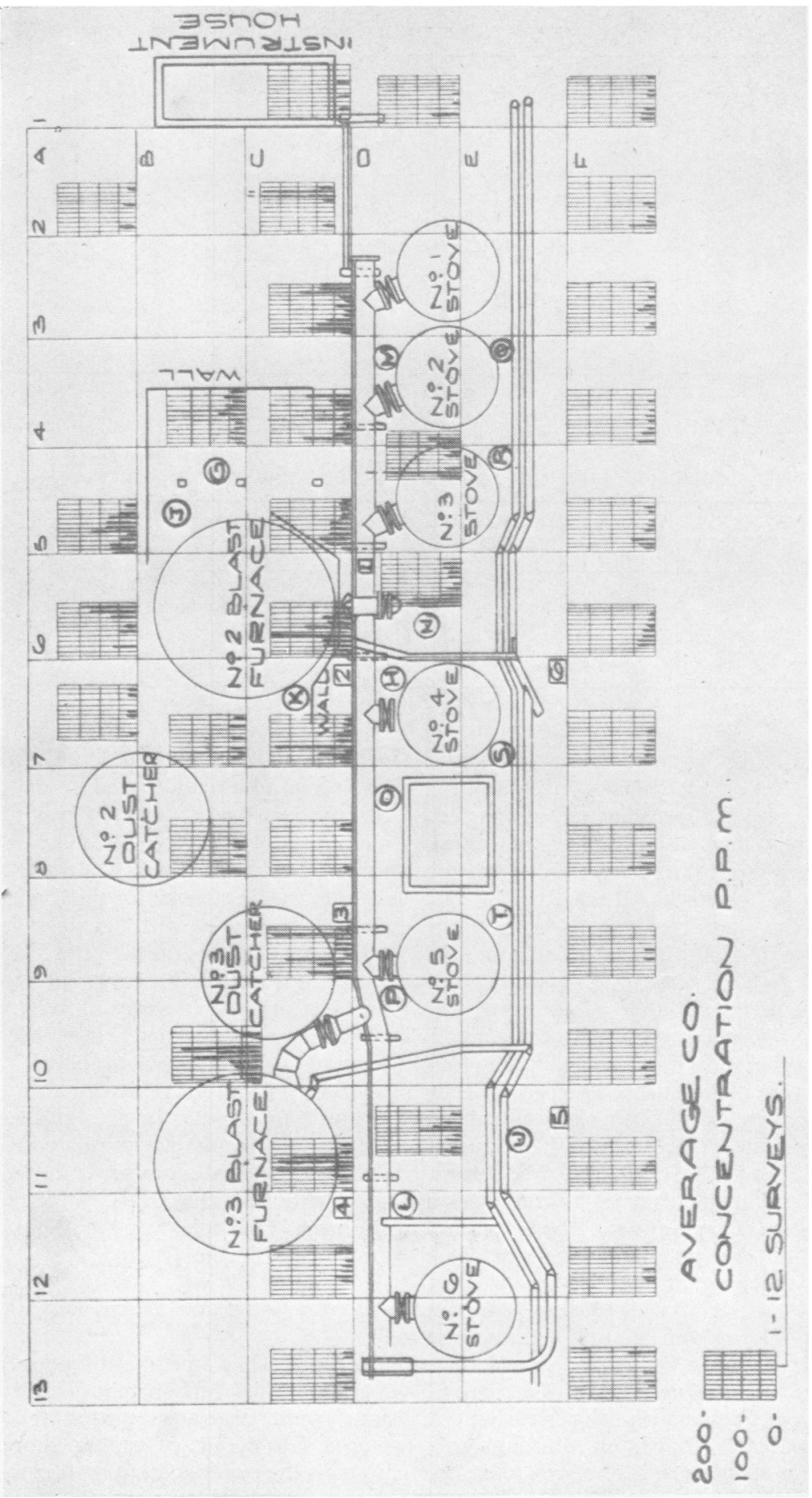


TABLE 2

CONCENTRATION OF CO AS RECORDED AT 14 EXPLORATORY POINTS

\begin{tabular}{|c|c|c|c|c|c|c|c|c|}
\hline \multirow{2}{*}{$\begin{array}{c}\text { Sampling Point } \\
\text { (see Fig. 2) }\end{array}$} & \multicolumn{7}{|c|}{ Number of Times CO Concentration (p.p.m.) was } & \multirow{2}{*}{$\begin{array}{c}\text { Total No. } \\
\text { of } \\
\text { Observations }\end{array}$} \\
\hline & $0-49$ & $50-99$ & $100-199$ & $200-299$ & $300-399$ & $400-499$ & 500 and over & \\
\hline $\begin{array}{l}\mathbf{G} \\
\mathbf{H} \\
\mathbf{J} \\
\mathbf{K} \\
\mathbf{L} \\
\mathbf{M} \\
\mathbf{N} \\
\mathbf{O} \\
\mathbf{P} \\
\mathbf{Q} \\
\mathbf{R} \\
\mathbf{S} \\
\mathbf{T} \\
\mathbf{U}\end{array}$ & $\begin{array}{r}308 \\
285 \\
192 \\
2,472 \\
86 \\
399 \\
252 \\
213 \\
218 \\
24 \\
24 \\
1,000 \\
24 \\
24\end{array}$ & $\begin{array}{l}40 \\
\\
56 \\
30 \\
37 \\
3 \\
= \\
= \\
= \\
=\end{array}$ & $\begin{array}{l}\frac{7}{\square} \\
\overline{1} \\
\bar{z} \\
\bar{z} \\
= \\
=\end{array}$ & $\begin{array}{l}\bar{z} \\
\bar{z} \\
\overline{1} \\
\bar{z} \\
\bar{z} \\
\bar{z}\end{array}$ & $\begin{array}{l}= \\
= \\
= \\
= \\
= \\
= \\
=\end{array}$ & $\begin{array}{l}= \\
= \\
\overline{1} \\
= \\
= \\
= \\
=\end{array}$ & $\begin{array}{l}= \\
= \\
= \\
= \\
= \\
= \\
=\end{array}$ & $\begin{array}{r}308 \\
332 \\
192 \\
2,472 \\
142 \\
432 \\
289 \\
216 \\
218 \\
24 \\
24 \\
1,000 \\
24 \\
24\end{array}$ \\
\hline
\end{tabular}

TABLE 3

CONCENTRATION OF CO AS RECORDED AT SIX FIXED POINTS

\begin{tabular}{|c|c|c|c|c|c|c|c|c|}
\hline \multirow{2}{*}{ Fixed Point } & \multicolumn{7}{|c|}{ Number of Times CO Concentration (p.p.m.) was } & \multirow{2}{*}{$\begin{array}{c}\text { Total No. } \\
\text { of } \\
\text { Observations }\end{array}$} \\
\hline & $0-49$ & $50-99$ & $100-199$ & 200-299 & 300-399 & $400-499$ & 500 and over & \\
\hline $\begin{array}{l}1 \\
2 \\
3 \\
4 \\
5 \\
6\end{array}$ & $\begin{array}{r}6,235 \\
9,744 \\
10,233 \\
10,206 \\
10,348 \\
10,330\end{array}$ & $\begin{array}{r}405 \\
614 \\
151 \\
134 \\
82 \\
99\end{array}$ & $\begin{array}{r}100 \\
82 \\
33 \\
45 \\
10 \\
11\end{array}$ & $\begin{array}{l}\frac{45}{13} \\
32 \\
-\end{array}$ & $\begin{array}{r}\frac{19}{6} \\
\frac{18}{-}\end{array}$ & $\begin{array}{r}25 \\
2 \\
5 \\
-\end{array}$ & $\begin{array}{l}\frac{83}{2} \\
- \\
-\end{array}$ & $\begin{array}{r}6,912 \\
10,440 \\
10,440 \\
10,440 \\
10,440 \\
10,440\end{array}$ \\
\hline
\end{tabular}

During a period of 32 days, the instrument cycled regularly, except for certain breaks in continuity, and the results which were recorded are summarized in Table 3. For nine days at the end of the experimental period, fixed point No. 1 was connected to a clean air source in order to check the zeroing characteristic of the instrument; consequently the number of samples analysed at this point is smaller than at the other five. Cycling was stopped when necessary for maintenance and checking of the apparatus and while special surveys were being made.

Twelve probe surveys, each of approximately four hours' duration, were made during this period using the following procedure. On a scale plan of the blast furnaces and stoves area (Fig. 2) a grid of squares coded A.1 to F.13, each $24 \mathrm{ft}$. $(7 \cdot 3 \mathrm{~m}$.) side dimension, was drawn, and each corner of a square was a potential point for sampling with the extension probe. Several of the potential locations were 'blanked out' by the plant itself, i.e., by furnaces, stoves, buildings, etc., and the 37 final effective ground level sampling positions on grid reference are shown in Figure 2. In order to randomize the sampling procedure during the probe surveys, different routes were followed on each occasion. A survey took approximately four hours, although only a few minutes were spent at any one grid reference position. The sampling line, with $300 \mathrm{ft}$. $(91 \mathrm{~m}$.) of extension tubing and the copper tubing of a fixed point also in circuit, varied in length, depending on the fixed point to which it was attached, up to a maximum of 600 feet $(182 \mathrm{~m}$.). It was found that, for this maximum length, three minutes was an adequate time interval for the line back to the instrument to be flushed with the air under test at the grid position. Accordingly, after moving to a new sampling position, three minutes were allowed for flushing, and then a series of five readings was taken on the extension meter at subsequent 30 -second intervals. Therefore sampling at any one grid reference position represented a 'random' event lasting two minutes in a total survey time of four hours. The results are presented in Figure 2.

During normal monitoring in the period following completion of the trials, information concerning abnormal incidents was recorded. Some examples are given in Table 4.

\section{Discussion}

No published information concerning a monitoring system for carbon monoxide in a blast furnace area could be traced during the field trials, and indeed few details of carbon monoxide concentrations in the various sections of a blast furnace area were available. Consequently, the information from 
TABLE 4

CONCENTRATION OF CO AS RECORDED DURING ABNORMAL INCIDENTS

\begin{tabular}{|c|c|c|c|c|c|c|c|c|c|c|}
\hline \multirow[b]{2}{*}{ Event } & \multirow{2}{*}{$\begin{array}{l}\text { Fixed } \\
\text { Point }\end{array}$} & \multirow{2}{*}{$\begin{array}{c}\text { Period } \\
\text { of Observa- } \\
\text { tion } \\
\text { (hours) }\end{array}$} & \multirow[b]{2}{*}{ Remarks } & \multicolumn{6}{|c|}{ Number of Times CO Concentration (p.p.m.) was } & \multirow{2}{*}{$\begin{array}{c}\text { Total No. } \\
\text { of } \\
\text { Observations }\end{array}$} \\
\hline & & & & $0-99$ & $100-199$ & 200-299 & $300-399$ & $400-499$ & $\begin{array}{c}500 \text { and } \\
\text { over }\end{array}$ & \\
\hline \multirow{2}{*}{$\mathbf{A}$} & 2 & $00.00-04.00$ & B.F. wall up & 79 & 17 & - & - & - & - & 96 \\
\hline & 2 & $04.00-08.00$ & B.F. wall down & 12 & 37 & 24 & 17 & 4 & 2 & 96 \\
\hline \multirow{2}{*}{ B } & 3 & $17.10-18.10$ & Emptying dust catcher & - & - & - & 4 & 7 & 13 & 24 \\
\hline & 3 & $13.20-15.20$ & Emptying dust catcher & 8 & 15 & 4 & 4 & 1 & 16 & 48 \\
\hline \multirow[b]{2}{*}{ C } & 4 & $20.10-22.20$ & Stove 6 on blast & 10 & 32 & 10 & - & - & - & 52 \\
\hline & 4 & $\begin{array}{l}22.20-02.50 \\
02.50-05.00\end{array}$ & $\begin{array}{l}\text { Stove } 6 \text { off blast (on gas) } \\
\text { Stove } 6 \text { on blast }\end{array}$ & $\begin{array}{r}105 \\
12\end{array}$ & $\begin{array}{r}3 \\
37\end{array}$ & $\overline{2}$ & $\overline{1}$ & 二 & 二 & $\begin{array}{r}108 \\
52\end{array}$ \\
\hline
\end{tabular}

the proving trials and from the subsequent period of normal monitoring was of great use in future planning. Recently, during the preparation of this report, a description of a similar monitoring system in the furnace-control instrument room of a research facility of an American steel corporation has appeared (Industrial Heating, 1964).

Siting of Fixed Sampling Points.-The provisional siting of the six fixed points had been discussed and agreed in the light of the preliminary results obtained with an extension probe and knowledge of the plant lay-out. The results obtained during the special probe surveys (Fig. 2) were studied in conjunction with the results obtained from continuous operation of the instrument in order to review the suitability of the provisional choices. The siting of points 5 and 6 had been determined by management because gassing incidents had occurred in those areas, and consequently, despite the low readings obtained, the points remained unchanged. Point 1 was moved to a new position midway between D.3 and D.4 on the grid. The other positions were confirmed.

Recorded Levels. - The bulk of the readings were in the range of 0 to 49 p.p.m.

Readings of 200 p.p.m. and over were studied specially, and, as can be seen from Table 3, they were noted at positions 1,3 , and 4 on 172,23 , and 55 occasions respectively. These included readings of 500 p.p.m. and over at positions 1 and 3 on 83 and two occasions respectively. It was found that all the readings at position 1 occurred during one period of 17 hours and were related to one event. A similar analysis of the readings at positions 3 and 4 showed that they were related to three and four events respectively. In total, during a 32-day period, eight events caused all the readings of 200 p.p.m. and over recorded in Table 3.
In Table 4, details of three further special events are given.

Event A related to the demolition of the damaged footing wall on No. 2 blast furnace. This area was sampled by fixed point 2. Comparison of the readings obtained during two representative four-hour periods showed no readings of 200 p.p.m. or over before demolition and $49 \%$ of readings in this range after demolition.

Event B showed the effect of emptying the dust catcher in the vicinity of fixed point 3 and indicated the necessity for men to wear breathing apparatus when engaged on this job.

Event $\mathrm{C}$ related to changes in operation of No. 6 stove in the area covered by fixed point 4 . When 'on gas', no readings of 200 p.p.m. or over were recorded, but when 'on blast', $13 \%$ of readings exceeded this level. These findings indicated that a valve was leaking.

Therefore the persistence of readings of 200 p.p.m. and over could be taken as an indication that some abnormal incident had occurred.

Fluctuations in Concentrations.- The results of the probe surveys showed that, in general, short-term fluctuations at a particular point were not great. However, it was possible for fluctuations above and below 200 p.p.m. to occur in a two-minute period.

Alarm Levels.-The theoretically derived alarm levels of 200 p.p.m. and 500 p.p.m. were considered in the light of the information gained during the use of the instrument as described. Fluctuations around the 200 p.p.m. level occurred only rarely, and generally when the level was exceeded it was an indication of a definite incident, leading to repeated readings at this or higher levels. It was unnecessary to give a warning of the occasional fluctuation exceeding 200 p.p.m., and means of avoiding this were considered. 
Concentrations of 500 p.p.m. could be inhaled continuously for $20 \mathrm{~min}$. before the symptom of headache was produced, and with lower concentrations the time got progressively longer. Three consecutive signals from an area being sampled could occur in from 5 to $7 \frac{1}{2}$ minutes. Consequently, although the relevant alarm light on the instrument panel would be switched on each time the level of 200 p.p.m. was exceeded, it was agreed to modify the apparatus so that the alarm light at the sampling position would be energized when the level had been exceeded on three consecutive occasions.

The success of this proposal also depended on the provision of an urgent warning at the higher level. It would be possible for concentrations between 200 p.p.m. and 499 p.p.m. to be present for $7 \frac{1}{2} \mathrm{~min}$. without a warning of either type at the sampling point, but this was acceptable in view of the time lag of $20 \mathrm{~min}$. or more before the onset of symptoms at this level. In the event of a more rapid gas leak, the auditory alarm would sound at 500 p.p.m.

As already indicated, the levels were chosen for medical reasons. It was of interest to learn from blast furnace management that their establishment led to no practical process difficulties.

\section{Conclusions}

The monitoring equipment comprising the Mines Safety Appliances Model 200 infra-red analyser, pumping system, recorder, extension meter, and alarm unit proved satisfactory for use in a blast furnace area.

The equipment provided: $(a)$ an alarm system to warn blast furnace personnel of dangerous or potentially dangerous concentrations of carbon monoxide, and to alert those responsible for ensuring safe working conditions; (b) information on the continuous chart recordings of use to production management, engineers, safety, and medical per- sonnel; (c) a method for checking plant or specific areas where gas leaks were suspected by use of the extension meter.

Two levels of alarm were accepted: (a) a visual alarm if a carbon monoxide level of 200 p.p.m. was exceeded at one sampling point on three consecutive occasions. At this level, work could safely continue for a limited period, but the reason for the raised level should be established; $(b)$ an auditory alarm if a level of 500 p.p.m. was exceeded on any sampling occasion. At this level, immediate action would be necessary, those in the area withdrawing or protecting themselves with breathing apparatus and those responsible for safety acting to control the source of carbon monoxide.

The authors thank the General Management of Messrs. Richard Thomas and Baldwins, Ltd., especially Mr. W. F. Gilbertson and Mr. C. G. Davies, for making the project possible. In addition, they wish to express appreciation of the help received from the Staff at Redbourn Works, particularly those of the Blast Furnace Department and the Instrument Section.

Finally, the help given by Mr. D. H. Walters, formerly of the Occupational Hygiene Unit, Richard Thomas and Baldwins, Ltd., during the major part of the project is gratefully acknowledged.

\section{REFERENCES}

Beatty, R. L. (1955). Methods for Detecting and Determining Carbon Monoxide. U.S. Bureau of Mines, Bull. 557.

Farmer, C. J., and Crittenden, P. J. (1929). J. Industr. Hyg., 11, 329.

H.M. Ćhief Inspector of Factories (1963). Annual Report of the Chief Inspector of Factories on Industrial Health. London, H.M.S.O.

Industrial Heating (1964). Detecting and measuring carbon monoxide at pilot blast furnace plant. Industrial Heating, 31, 1906, 1908,

Jones, J. G., and Walters, D. H. (1962). Ann. occup. Hyg., 5, 221

Katz, M. (1958). Canad. med. Ass. J., 78, 182.

Memorandum on Carbon Monoxide Poisoning (1951). London, H.M.S.O.

Pfrender, R. E. (1962). Industr. Med. Surg., 31, 99.

Schulte, J. H. (1963). Arch. environm. Hlth, 7, 524.

Spencer, T. D. (1962). Ann. occup. Hyg., 5, 231.

Threshold Limits Committee of the American Conference of Governmental Industrial Hygienists (1964). 